\title{
Effect of Carica papaya Leaf Extract on Serum Lipids and Liver Metabolic Parameters of Rats Fed a High Cholesterol Diet
}

\author{
Alma M. Zetina-Esquivel1, Carlos A. Tovilla-Zárate², Crystell Guzmán-Garcia1, \\ Arturo Rodríguez-Hernández ${ }^{3}$, Andrés E. Castell-Rodríguez ${ }^{4}$, Jorge L. Ble-Castillo", \\ Angela Avila-Fernandez ${ }^{1}$, Isela E. Juárez-Rojop${ }^{1 *}$, Juan C. Díaz-Zagoya ${ }^{4}$ \\ ${ }^{1}$ Centro de Investigación, División Académica de Ciencias de la Salud, Universidad Juárez Autónoma de Tabasco, \\ Villahermosa, México \\ ${ }^{2}$ División Académica Multidisciplinaria de Comalcalco, Universidad Juárez Autónoma de Tabasco, Comalcalco, \\ México \\ ${ }^{3}$ Unidad de Medicina Familiar 10, Instituto Mexicano del Seguro Social, Xalapa, México \\ ${ }^{4}$ División de Investigación, Facultad de Medicina, Universidad Nacional Autónoma de México, México, D. F., \\ México \\ Email: ${ }^{\text {iselajuarezrojop@hotmail.com }}$
}

Received 31 July 2015; accepted 22 September 2015; published 25 September 2015

Copyright (C) 2015 by authors and Scientific Research Publishing Inc.

This work is licensed under the Creative Commons Attribution International License (CC BY).

http://creativecommons.org/licenses/by/4.0/

c) (i) Open Access

\section{Abstract}

Hyperlipidemia plays an important role in the development of atherosclerosis, the main cause of death in the world. In this study, the lipid-lowering effect of Carica papaya leaf in rats fed with a high cholesterol diet was evaluated. Daily doses of C. papaya extract $0,31,62 \mathrm{or} 125 \mathrm{mg} / \mathrm{kg}$ body weight were orally administered in $300 \mu$ polyethylene glycol to hypercholesterolemic rats; it was also administered $62 \mathrm{mg} / \mathrm{kg}$ body weight of the extract to rats with normal diet. After a 20-day treatment, the animals were sacrificed; blood and liver were analyzed. Hypercholesterolemic rats showed an increased serum and liver cholesterol, triacylglycerols, and atherogenic index. The $C$. papaya extract produced a significant decrease of serum and liver cholesterol concentrations in hypercholesterolemic rats, but did not modify serum or liver triacylglycerols; however, the extract reduced the atherogenic index in a dose-dependent manner. C. papaya treatment decreased LDL-C and increased HDL-C in serum significantly. When the oxygen consumption was evaluated in phosphorylating and resting states, the respiratory control in hypercholesterolemic rats mitochondria was lower than in normal diet rats. However, a higher respiratory control in hypercho-

\footnotetext{
${ }^{*}$ Corresponding author.
}

How to cite this paper: Zetina-Esquivel, A.M., et al. (2015) Effect of Carica papaya Leaf Extract on Serum Lipids and Liver Metabolic Parameters of Rats Fed a High Cholesterol Diet. Health, 7, 1196-1205. 
lesterolemic rats mitochondria was observed after $\mathrm{C}$ papaya treatment. The liver morphological data are in accordance with serum and liver biochemical values. Our data support that $C$. papaya has a significant hypocholesterolemic action and HDL-C raising effect on rats fed with a cholesterol-rich diet, however, the precise metabolites responsible of this effect remain unknown.

\section{Keywords}

\section{Serum Lipids, Carica papaya, Cholesterol, Mitochondria}

\section{Introduction}

Hyperlipidemia is the major contributor to cardiovascular disease (CVD). The risk factors for CVD include obesity, elevated blood pressure, high blood cholesterol, and diabetes; CVDs are among the leading causes of global mortality and morbidity; their haunting trend has been predicted to rise, parallel to higher economic development [1]. The improvement of patient lipid profile is a challenge to decrease CVD mortality through prevention of atherosclerotic injuries. Several drugs help to reduce plasma LDL-C levels, but these synthetic medications also produce adverse effects such as diarrhea, nausea, myositis and abnormal liver function [2]. Moreover, some patients are resistant or intolerant to conventional pharmacotherapy. Therefore, alternative approaches are eagerly needed; plant-based therapies attract much interest as they are effective in reducing lipid levels [3]. The treatment for hypercholesterolemia and CVDs with medicinal plants has increased and seems to produce lower undesirable side effects [4]. Several reports have shown that herbal medicine reduces lipid peroxidation in blood, has anti-cancer activity in vitro and it is useful for treating infectious disease [5]. Herbal medicine is used by up $80 \%$ population from developing countries, but few scientific studies have explored the safety and efficacy of these traditional remedies [1]. In this line, the papaya leaves have been used as a remedy for various disorders like cancer and infectious diseases [6]. Moreover, papaya leaf methanol extract showed a HDL-C raising effect that improving the CVD risks [7]. However, to our knowledge, no report of its hypolipidemic effect has been published. The objective of this study was to evaluate the hypolipidemic action of Carica papaya extract and its action on liver metabolic parameters of hypercholesterolemic rats.

\section{Materials and Methods}

\subsection{Chemical Compounds and Plant Products}

All chemicals were purchased from Sigma (St Louis, Mo, USA). Other chemicals of analytical grade were obtained from Merck. Kits for different enzyme assays were purchased from Biosystems S.A., Mexico. The Carica papaya leaves were collected from June to September 2012 from Cintalapa, in the state of Chiapas, Mexico.

\subsection{Preparation of $C$. papaya Leaf Chloroform Extract}

The leaves of C. papaya were washed with tap water and cut into small slices. The slices were powdered after air-drying. A $100 \mathrm{~g}$ dry sample was placed in a Soxhlet system, the extraction was conducted 8 hours with 500 $\mathrm{mL}$ of chloroform. Subsequently, the solvent was evaporated in vacuum until the extract was completely dried and was preserved at $-20^{\circ} \mathrm{C}$. Finally, $10 \mathrm{~g}$ of semi-solid mass was obtained.

\subsection{Animals and Their Diets}

Experiments were performed using male Wistar rats to avoid any gender differences due to sexual hormones, in the case of female rats [8]. At 7 weeks of age and $180-200 \mathrm{~g}$ body weight were maintained under controlled housing conditions: $55 \%$ humidity, $21^{\circ} \mathrm{C} \pm 1{ }^{\circ} \mathrm{C}$ temperature and a $12-12 \mathrm{~h}$ light-dark cycle, with free access to food and water. All experiments started at the same hour (10:00 AM) and they complied with the Guidelines on Ethical Standards for the investigation in animals; the project was approved by the local Internal Committee for the care and use of laboratory animals (003-13/CICUAL/DACS). The normal diet (ND), from Harlan Laboratories, contained $18.6 \%$ protein, $44.2 \%$ carbohydrates, $6.2 \%$ fat. The hypercholesterolemic diet (HD) included $2 \%$ 
cholesterol, $0.6 \%$ sodium deoxycholate added to grinded ND.

\subsection{Study Design}

The design of this study included the following groups ( $=8$ each one): 1$)$ ND: Normal diet; 2$)$ ND + C. papaya extract: (62 mg/kg; ND + 62); 3) HD: Hypercholesterolemic diet; 4) HD + C. papaya extract (31 mg/kg; HD + 31); 5) HD + C. papaya extract: $(62 \mathrm{mg} / \mathrm{kg} ; \mathrm{HD}+62) ; 6) \mathrm{HD}+$ C. papaya extract: $(125 \mathrm{mg} / \mathrm{kg} ; \mathrm{HD}+$ 125).

Animals were given free access to water and food during the 20-day experimental time. At the end of treatment and after $12 \mathrm{~h}$ food withdrawal, the rats were sacrificed by decapitation. The liver was removed, weighted and $0.5 \mathrm{~g}$ of tissue was used for biochemical analyses, a small part was fixed in $10 \%$ buffered formaldehyde solution and the remaining tissue was used to isolate mitochondria and to assay respiratory function. C. papaya extract doses (31, 62 and $125 \mathrm{mg} / \mathrm{kg} /$ day) were given daily by oral gavage in $300 \mu \mathrm{l}$ polyethylene glycol. These dose were chosen in accordance with previous experiments from our laboratory.

\subsection{Biochemical Parameters}

Serum levels of glucose, cholesterol, triacylglycerols, high-density lipoprotein-cholesterol (HDL-C), aspartate aminotransferase (AST), alanine aminotransferase (ALT) and alkaline phosphatase (ALP) were evaluated. The atherogenic index (A.I.) was calculated according to the equations of Kim et al. [9]. Liver lipids were extracted according to the Folch et al. [10] procedure; triacylglycerols (TAG) and cholesterol concentrations were measured using enzymatic determination from BioSystems Laboratories.

\subsection{Mitochondria Isolation}

Hepatic tissue was washed twice with $250 \mathrm{mM}$ sucrose, $0.5 \mathrm{mM}$ HEPES, $0.5 \mathrm{mM}$ EGTA buffer (SHE), and homogenized in SHE, pH 7.2, employing approximately $5 \mathrm{~mL} / \mathrm{g}$ wet weight. Mitochondria were isolated by differential centrifugation and suspended with SHE to a final protein concentration of $0.5 \mathrm{mg} / \mathrm{mL}$, determined by the Bradford method [11].

\subsection{Oxygen Consumption}

Respiratory measurements of mitochondria were performed in $3.5 \mathrm{ml}$ of air-saturated medium with $5 \mathrm{mM}$ succinate, $2 \mathrm{mM} \mathrm{MgCl}_{2}, 2 \mathrm{mM} \mathrm{H}_{3} \mathrm{PO}_{4}, 2 \mathrm{mM}$ EGTA, $30 \mathrm{mM}$ HEPES, 0.1\% BSA, pH 7.2, at $24^{\circ} \mathrm{C}$. Oxygen consumption was determined using a Clark-type oxygen electrode. Data are expressed as the respiratory control (RC) ratio, which is a relative value of state 3 and state 4 that indicates the respiratory coupling in availability of ADP [12].

\subsection{Liver Histopathological Examination}

The histopathologic analysis was performed by light microscopy, staining with hematoxylin and eosin (HE). Other liver section was frozen and also sliced to be stained with Oil Red O to measure the steatosis areas in the liver by the Image Pro Plus 7.0 program [13].

\subsection{Statistical Analysis}

One-way analysis of variance (ANOVA) followed by Student-Newman-Keuls test was used to compare differences between treatments. Values were considered statistically significant when $\mathrm{p}<0.05$.

\section{Results}

\subsection{The Hypolipidemic and Antiatherogenic Effects of $C$. papaya Leaf}

We observed that administration of a cholesterol-rich diet (HD) produced high levels of plasma cholesterol $(249.3 \pm 6.4 \mathrm{mg} / \mathrm{dL})$ compared with normal diet (ND) $(74.3 \pm 2.2 \mathrm{mg} / \mathrm{dL})$; besides, the treatment with different doses of $C$. papaya extract (HD +31 , HD +62 and HD +125$)$ produced significant lower levels in a dose dependent manner $(\mathrm{p}<0.05)$ (Table 1$)$. On the other hand, serum TAG concentrations increased in HD $(77.3 \pm 7.2$ 
Table 1. Effects of C. papaya leaf on blood biochemical parameters of rats fed a cholesterol-enriched diet.

\begin{tabular}{|c|c|c|c|c|c|c|c|c|c|}
\hline $\begin{array}{l}\text { Treatment } \\
\text { C. papaya } \\
\text { (mg/kg) }\end{array}$ & $\begin{array}{c}\text { Gluc } \\
\text { (mg/dL) }\end{array}$ & $\begin{array}{c}\text { Chol } \\
\text { (mg/dL) }\end{array}$ & $\underset{\text { (mg/dL) }}{\text { TAG }}$ & $\begin{array}{l}\text { HDL-C } \\
\text { (mg/dL) }\end{array}$ & $\begin{array}{l}\text { LDL-C } \\
\text { (mg/dL) }\end{array}$ & $\begin{array}{c}\text { AST } \\
\text { (IU/L) }\end{array}$ & $\begin{array}{c}\text { ALT } \\
\text { (IU/L) }\end{array}$ & $\begin{array}{c}\text { ALP } \\
\text { (IU/L) }\end{array}$ & AI \\
\hline ND & $88 \pm 1.8$ & $74.3 \pm 2.2$ & $60.4 \pm 3.9$ & $34.9 \pm 3.9$ & $40 \pm 6.9$ & $186.4 \pm 4$ & $72.5 \pm 5.4$ & $174 \pm 18.3$ & $2.7 \pm 0.3$ \\
\hline ND + 62 & $75 \pm 6.2$ & $72.3 \pm 5.9$ & $61.2 \pm 2.6$ & $34.1 \pm 2.3$ & $27 \pm 2.8$ & $207.3 \pm 5.4$ & $68.3 \pm 5.6$ & $185 \pm 20.7$ & $2.2 \pm 0.1^{\mathrm{a}}$ \\
\hline HD & $106 \pm 2.4^{\mathrm{a}}$ & $249.3 \pm 6.4^{\mathrm{a}}$ & $77.3 \pm 7.2$ & $16.1 \pm 0.3^{\mathrm{a}}$ & $217 \pm 5.2^{\mathrm{a}}$ & $278 \pm 14^{\mathrm{a}}$ & $96.2 \pm 8.5^{\mathrm{a}}$ & $278 \pm 10^{\mathbf{a}}$ & $15.3 \pm 0.5^{\mathrm{a}}$ \\
\hline HD + 31 & $77 \pm 0.8^{\mathbf{b}}$ & $191.2 \pm 19.4^{\mathbf{b}}$ & $60 \pm 7.4$ & $24.6 \pm 2.6$ & $125 \pm 16^{\mathbf{b}}$ & $263 \pm 7.5$ & $85 \pm 2.4$ & $239 \pm 11$ & $10.2 \pm 0.7^{\mathrm{b}}$ \\
\hline HD + 62 & $96 \pm 2.5$ & $183.5 \pm 12.4^{\mathrm{b}}$ & $64.7 \pm 7.1$ & $23.2 \pm 2.6$ & $149 \pm 14^{b}$ & $254 \pm 8.8$ & $70.3 \pm 5.5^{\mathbf{b}}$ & $199.5 \pm 7.5^{\mathbf{b}}$ & $9.4 \pm 0.8^{\mathrm{b}}$ \\
\hline HD + 125 & $70 \pm 6.3^{\mathbf{b}}$ & $170 \pm 5.8^{\mathbf{b}}$ & $77.8 \pm 6.3$ & $27.2 \pm 1.2^{\mathbf{b}}$ & $127 \pm 5.3^{\mathbf{b}}$ & $270.4 \pm 3.0$ & $84 \pm 2$ & $257 \pm 12.8$ & $6.3 \pm 0.4^{b}$ \\
\hline
\end{tabular}

Data are expressed as mean \pm S.E.M.; $\mathrm{n}=8$. One-way analysis of variance (ANOVA) followed by Student-Newman-Keuls test $(\mathrm{p}<0.05)$. ${ }^{\mathrm{a}}$ Statistically different from normal diet (ND); ${ }^{b}$ statistically different from hypercholesterolemic (HD) rats ( $\left.<0.05\right)$. Glu (Glucose), Chol (Cholesterol), TAG (Tryacylglyerols), LDL-C (Low-density lipoprotein cholesterol), HDL-C (High-density lipoprotein cholesterol), AST (aspartate aminotransferase), ALT (alanine aminotransferase), ALP (alkaline phosphatase), AI (atherogenic index).

$\mathrm{mg} / \mathrm{dL})$ in comparison with ND $(60.4 \pm 3.9 \mathrm{mg} / \mathrm{dL})$ but the administration of $C$. papaya extract did not decrease significantly TAG levels in HD + 31 and HD + 62 in comparison with HD while HD + 125 showed similar TAG levels to those of HD rats (Table 1 ).

The HD rats showed a decrease in serum HDL-C levels $(16.1 \pm 0.3 \mathrm{mg} / \mathrm{dL})$ compared with ND $(34.9 \pm 3.9$ $\mathrm{mg} / \mathrm{dL}$ ); in addition, the three doses of $C$. papaya increased HDL-C levels with respect to HD (Table 1), however, this increment did not reach the ND values. The LDL-C levels increased in HD (217 $\pm 5.2 \mathrm{mg} / \mathrm{dl}) \mathrm{in}$ comparison with ND $(40 \pm 6.9 \mathrm{mg} / \mathrm{dL})$; besides, the groups treated with C. papaya: HD + 31, HD + 62 and HD + 125 had a significant decrease (125 $\pm 16 \mathrm{mg} / \mathrm{dL}, 149 \pm 14 \mathrm{mg} / \mathrm{dL}$ and $127 \pm 5.3 \mathrm{mg} / \mathrm{dL}$, respectively) in comparison with HD, but the values did not reach those levels observed in ND. The atherogenic index (AI) was increased in HD $(15.3 \pm 0.5)$ in comparison to ND $(2.7 \pm 0.3)$. On the contrary, the AI was significantly reduced by $C$. papaya in a dose dependent manner (10.2 $\pm 0.7,9.4 \pm 0.8,6.3 \pm 0.4$; respectively) when compared to HD $(\mathrm{p}<0.05)$.

Moreover, HD administration induced a considerable increase in serum AST, ALT and ALP activities (278 \pm 14, $96.2 \pm 8.5$ and $278 \pm 10 \mathrm{IU} / \mathrm{L}$, respectively) in comparison with ND (186.4 $\pm 4,72.5 \pm 5.4$ and $174 \pm 18.3$ IU/L, respectively). C. papaya administration produced a significant decrease in ALT and ALP activities in HD + 62 (70.3 55.5 and $199.5 \pm 7.5 \mathrm{IU} / \mathrm{L}$, respectively) in comparison with HD (p < 0. 05) (Table 1$)$.

\subsection{Liver Cholesterol and Triacylglycerols}

The hepatic cholesterol levels of HD (13 $\pm 0.6 \mathrm{mg} / \mathrm{g}$ tissue) were significantly higher than those in ND (6 \pm 0.2 $\mathrm{mg} / \mathrm{g}$ tissue). In C. papaya-treated groups 31, 62 and 125 (9.9 $\pm 0.5,9.4 \pm 0.4,10 \pm 0.4 \mathrm{mg} / \mathrm{g}$ tissue; respectively) cholesterol levels were lower with respect to HD ( $<<0.05)$. The liver TAG levels increased in HD (11 \pm 0.2 $\mathrm{mg} / \mathrm{g}$ tissue) compared to ND (7.3 $\pm 0.6 \mathrm{~g} \mathrm{mg} / \mathrm{g}$ tissue). However, a non-significant decrease was observed in $C$. papaya-treated groups 31, 62 and 125 (9.9 \pm 0.4, $8.9 \pm 0.7,9.5 \pm 0.8 \mathrm{mg} / \mathrm{g}$ tissue, respectively).

\subsection{Liver Histopathological Examination (Hematoxylin \& Eosin)}

Hepatocytes from ND rats showed normal cell structure with well-preserved cytoplasm (Figure 1(a)), containing small fat vesicles and glycogen granules, with no signs of fibrosis. The liver morphology of ND + 62 rats (Figure 1(b)) showed similar characteristics than those observed in ND rats. On the other hand, HD rats presented a multivesicular hepatic steatosis, with abundant fat vesicles and glycogen granules especially around the central veins (Figure $\mathbf{1 ( c )}$ ). The liver morphology of HD + 31 and HD + 62 rats (Figure 1(d) \& Figure 1(e), respectively) exhibited moderate changes including a lower grade of steatosis in comparison with that observed in HD rats. The lipid-lowering effect of C. papaya extract was worthless in HD + 125 rats (Figure 1(f)).

\subsection{Oil Red O Staining}

The ND livers (Figure 2(a)) showed a minimal amount of lipid droplets, as well as the liver of ND +62 rats 

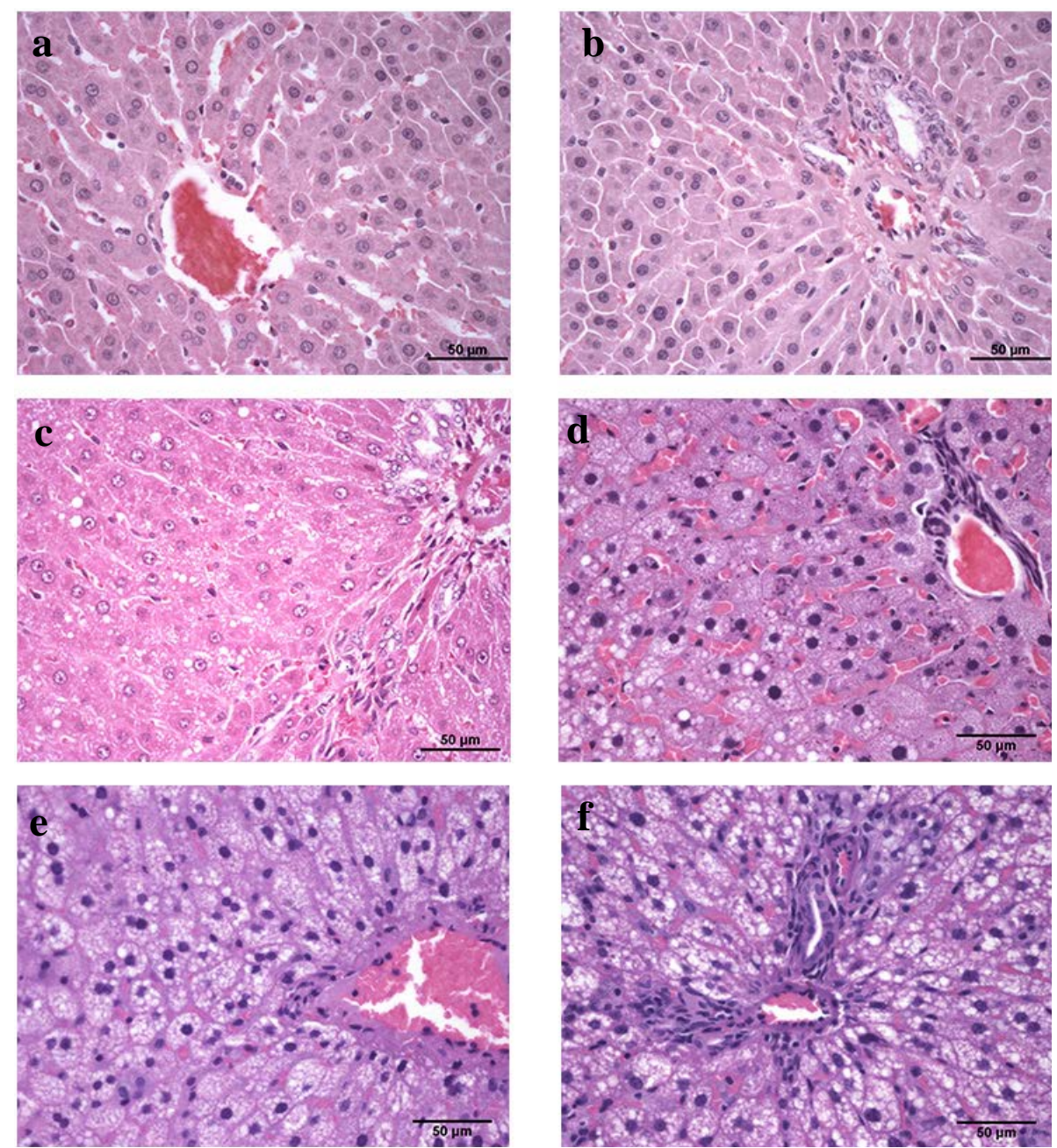

Figure 1. Liver histopathological examination from rats treated with a cholesterol-enriched diet and C. papaya extract, stained with hematoxylin and eosin (HE, bar $=50 \mu \mathrm{m})$. (a) Normal diet (ND) hepatocytes show a minimal amount of lipid droplets. (b) ND + C. papaya extract $(62 \mathrm{mg} / \mathrm{kg}$ ) liver cells have similar characteristics to ND. (c) Hypercholesterolemic diet (HD) the cells show more lipid droplets accumulated in vacuoles. (d) HD + C. papaya extract (31 mg/kg) hepatocytes show a lower grade of liver steatosis than HD. (e) HD + C. papaya extract $(62 \mathrm{mg} / \mathrm{kg}$ ) these cells show the lowest grade of steatosis in comparison with HD. (f) $\mathrm{HD}+$ C. papaya extract $(125 \mathrm{mg} / \mathrm{kg})$.

(Figure 2(b)). In HD group the liver shows a multivesicular steatosis (Figure 2(c)). HD + 31 and HD + 62 rats (Figure 2(d) \& Figure 2(e), respectively) showed a lower grade of liver steatosis than HD group. Again, the effect of $C$. papaya extract on liver lipids was worthless in HD + 125 group (Figure 2(f)). Additionally, the assay of the fatty area in hepatocytes of HD rats $\left(198 \pm 3.03 \mu \mathrm{m}^{2}\right)$ was the highest value among all groups, in contrast to ND group values $\left(4.48 \pm 0.6 \mu \mathrm{m}^{2}\right)$. On the other hand, $\mathrm{HD}+31, \mathrm{HD}+62$ and $\mathrm{HD}+125$ groups showed minor lipid areas (136 $\pm 19.9,76.71 \pm 8.14$ and $133 \pm 9.93 \mu \mathrm{m}^{2}$, respectively) than that observed in HD rats (198 \pm $3.03 \mu \mathrm{m}^{2}$ ). The HD +62 group showed the most important decrease of liver lipids.

\subsection{Respiratory Control}

The respiratory control (RC) was lower in the liver mitochondria of HD rats $(2 \pm 0.2)$ in comparison with ND rats $(3 \pm 0.1)$. Groups $\mathrm{HD}+31, \mathrm{HD}+62$ and $\mathrm{HD}+125$ showed a significant increase of oxygen consumption $(3.4 \pm 0.06,3.23 \pm 0.09$ and $3.32 \pm 0.09$, respectively) in comparison with non-treated HD rats $(1.97 \pm 0.2)$ (Figure 3). 

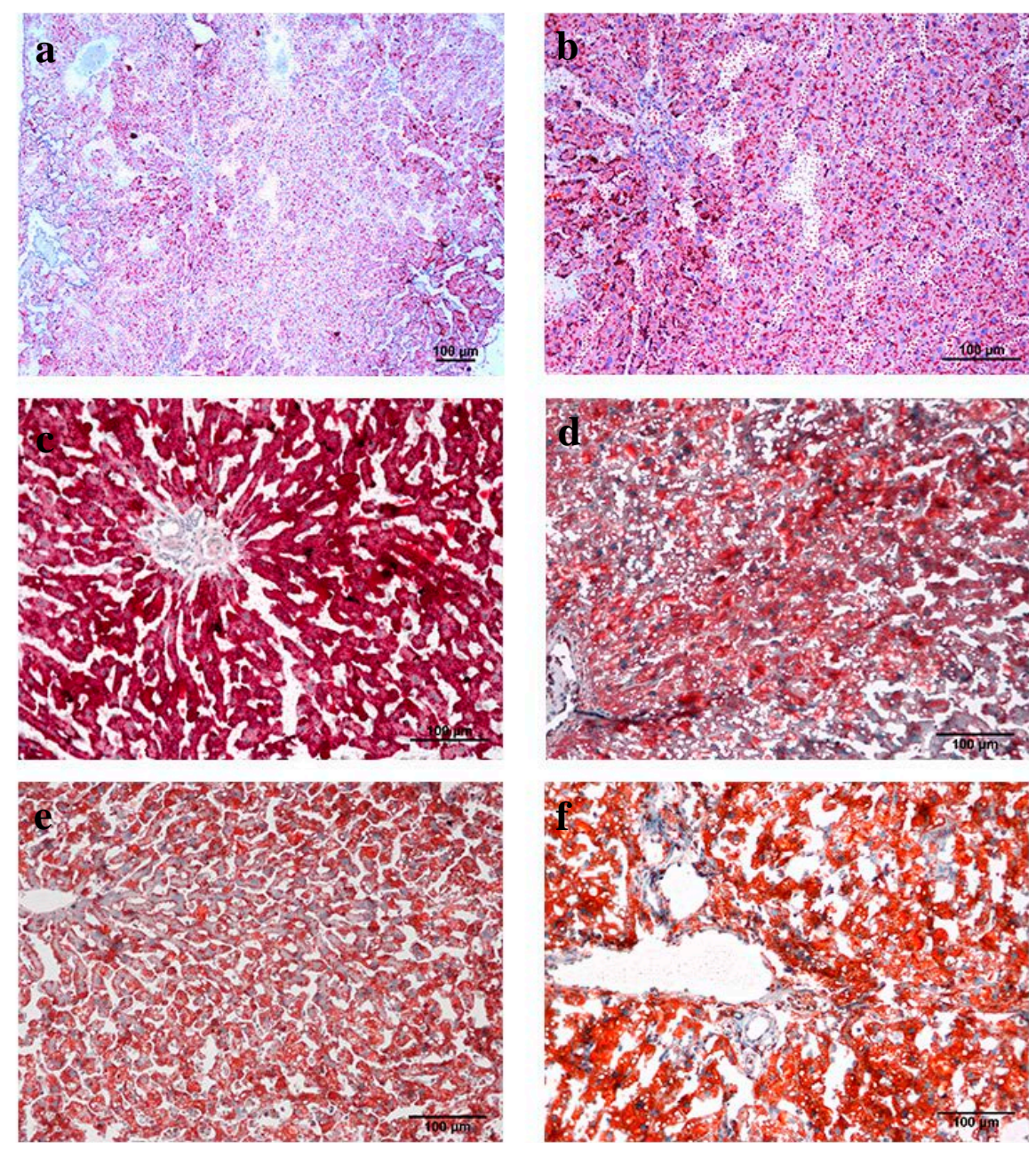

Figure 2. Liver histopathological examination from rats fed a cholesterol-enriched diet and $C$. papaya extract, stained with Oil red O (bar $=100 \mu \mathrm{m})$. (a) Normal diet (ND) hepatocytes show a minimal amount of lipid droplets. (b) ND + C. papaya extract (62 mg/kg) Liver cells have similar characteristics to ND. (c) Hypercholesterolemic diet (HD) the cells show more lipid droplets accumulated in vacuoles. (d) HD + C. papaya extract (31 mg/kg) hepatocytes show a lower grade of liver steatosis than HD. (e) HD + C. papaya extract $(62 \mathrm{mg} / \mathrm{kg})$ these cells show the lowest grade of steatosis in comparison with HD. (f) HD + C. papaya extract $(125 \mathrm{mg} / \mathrm{kg})$; The lipid-lowering effect of $C$. papaya extract was worthless with this dose.

\section{Discussion}

The high prevalence of chronic metabolic diseases around the world is associated with hyperlipidemia and development of CVD. For this reason, there is a considerable interest in finding new safe hypolipidemic drugs to prevent cardiovascular complications

\subsection{The Hypolipidemic and Antiatherogenic Effects of $C$. papaya Leaf}

We observed that treatment with C. papaya extract decreased serum cholesterol of HD rats. Previous reports from our laboratory have shown that $C$. papaya leaf contains sterols among their main components. It is known that phytosterols with analogue structure to cholesterol may decrease cholesterol absorption displacing it from bile salt micelles and competing for intestinal absorption [14] [15]. Intestinal absorption plays a main role in the regulation of cholesterol homeostasis. It has been suggested that transporters can affect its intestinal absorption [16] [17]. Silva et al. in 2013 [18] observed a reduction of hepatic cholesterol after $\beta$-carotene supplementation to rats with a cholesterol-rich diet, an effect attributed to increased cholesterol fecal excretion. 


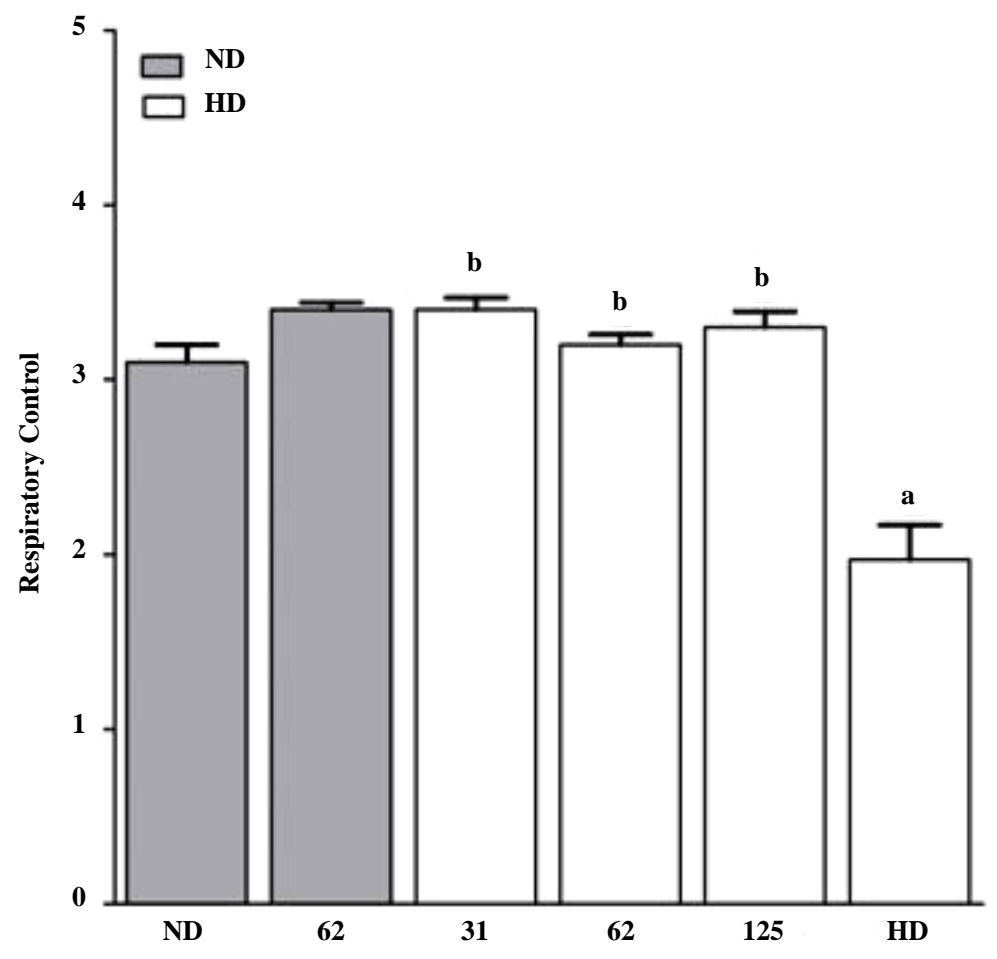

Figure 3. Effect of $C$. papaya leaf on respiratory control of liver mitochondria of rats on high cholesterol diet. Each bar is the mean \pm S.E.M. of eight animals. ${ }^{*} p<0.05$. Statistical analysis was done by One-way analysis of variance (ANOVA), followed by the Student-Newman-Keuls test. a Statistically different from control diet (ND) rats; 'statistically different from hypercholesterolemic (HD) rats $(\mathrm{p}<0.05)$.

Nowadays, the increase of serum LDL concentration and a high LDL/HDL ratio are considered atherogenic risk factors. In this sense, recent epidemiological and clinical studies have also shown a positive correlation between serum LDL-C levels and the risk of coronary heart disease [19] [20]. The administration of flavonoids to hyperlipidemic rats improves dyslipidemia [20], decreases the intestinal absorption of cholesterol, besides the reabsorption of bile acids and neutral sterols. In the case of $C$. papaya, this could be the mechanism for serum cholesterol improvement. On the other hand, when phytosterols were given to hypercholesterolemic patients a significant reduction of LDL-C was produced [19].

\subsection{Liver Cholesterol, Triacylglycerols and Histopathological Changes by $C$. papaya Leaf}

Liver is the main site for cholesterol homeostasis and a high fat diet increases the lipid levels in content of the liver. Previous studies have demonstrated that a cholesterol-rich diet can induce steatohepatitis in animal models [21]. Hepatic damage is related to deterioration of the hepatocyte membrane, which generates a reduction of its antioxidant and detoxification capacity [20]. In this study we observed that C. papaya administrated to HD rats reduced hepatic cholesterol.

This result is in accordance with other reports after plant extracts administration [21]. Other plant extracts given to hypercholesterolemic rats inhibited the 3-hydroxy-3-methylglutaryl-CoA reductase. In this study, the $C$. papaya extract given to HD rats did not reduce the liver TAG, a lacking effect also observed on serum TAG levels. Other studies suggest that plant extracts reduce hyperlipidemia and fatty liver through an increase of fatty acid oxidation, and lower TAG synthesis, which leads to a rise of steroid fecal excretion with minor alteration of cholesterol synthesis [22].

It's known that a cholesterol-rich diet can induce steatohepatitis in animal models; this damage is related to deterioration of the hepatocyte membrane, which generates a reduction of its antioxidant and detoxification capacity [20]. The increase in serum transaminases has been considered a marker of liver damage. In this study, 
serum ALT and ALP improved after C. papaya $(62 \mathrm{mg} / \mathrm{kg}$ ) treatment. Furthermore, the histopathological studies in HD + 62 liver showed a reduced damage due to decrease of cholesterol in hepatocyte. In this sense, other reports have informed that diminishing free-radicals production, after plant extract administration, may protect the liver from the high-cholesterol toxicity [23] [24]. Recently, other reports suggest that plant extracts can inhibit free fatty acid (FFA) transport into the liver and regulate FFA metabolism through the expression of related genes [24]. In our study we observed that $C$. papaya leaf extract significantly decreased serum glucose levels in $\mathrm{HD}+31, \mathrm{HD}+62$ and HD +125 compared with HD $(\mathrm{p}<0.05)$. Some studies have suggested that plant sterols may delay the glucose absorption by inhibiting intestinal enzymes that hydrolyze carbohydrates with the concomitant lower glycemia [14].

\subsection{Effect of $C$. papaya Leaf on the Respiratory Control}

It is known that mitochondria are affected by a high fat diet, presenting ultra-structural abnormalities and higher production of reactive oxygen species (ROS) that produce hepatic cellular damage [25] [26]. Our results showed that HD rats present a decrease of the respiratory control in comparison with ND rats. Other authors have reported a reduction in oxygen consumption, phosphorylation rate and hepatic mitochondria respiratory control in HD rats [26] [27]. We observed that C. papaya leaf administered to HD rats improved the respiratory control. There is evidence that flavonoids, saponins and polyphenols, raise the antioxidant system activity and reduce the nitric oxide production in the hypercholesterolemic rats. The $C$. papaya antioxidant effect may reduce the oxidative stress due to hypercholesterolemia, resulting in a reduction or a delay of the liver endothelial cells harm.

\section{Conclusion}

In the present study, the administration of $C$. papaya chloroform extract to rats with a cholesterol-rich diet showed a hypoglycemic and hypolipidemic effect, with reduction of the atherogenic index, minor hepatic damage and increased respiratory function of the hepatic mitochondria. We speculate that these effects can be due to the sterol content of C. papaya, which is effective to reduce dietary cholesterol absorption. Consequently, the $C$. papaya leaf extract could be considered, along with other lifestyle changes, as an alternative treatment for hypercholesterolemic patients. Further studies are required in order to characterize the active substances in the extract and to understand their mechanism of action.

\section{Acknowledgements}

The authors are in debt with Mical K García-Reyes who helped in the microscope observations. This study was supported in part by the Research Program to Assist and Consolidate Academic Groups (PFICA in Spanish), UJAT-2010-C06-10.

\section{References}

[1] Cholesterol Treatment Trialists’ (CTT) Collaboration, Fulcher, J., O’Connell, R., Voysey, M., Emberson, J., Blackwell, L., Mihaylova, B., Simes, J., Collins, R., Kirby, A., Colhoun, H., Braunwald, E., La Rosa, J., Pedersen, T.R., Tonkin, A., Davis, B., Sleight, P., Franzosi, M.G., Baigent, C. and Keech, A. (2015) Efficacy and Safety of LDL-Lowering Therapy among Men and Women: Meta-Analysis of Individual Data from 174,000 Participants in 27 Randomised Trials. The Lancet, 385, 1397-1405. http://dx.doi.org/10.1016/S0140-6736(14)61368-4

[2] Zhang, X., Wu, C., Wu, H., Sheng, L., Su, Y., et al. (2013) Anti-Hyperlipidemic Effects and Potential Mechanisms of Action of the Caffeoylquinic Acid-Rich Pandanus tectorius Fruit Extract in Hamsters Fed a High Fat-Diet. PloS One, 8, e61922. http://dx.doi.org/10.1371/journal.pone.0061922

[3] Kamesh, V. and Sumathi, T. (2012) Antihypercholesterolemic Effect of Bacopa monniera linn. on High Cholesterol Diet Induced Hypercholesterolemia in Rats. Asian Pacific Journal of Tropical Medicine, 5, 949-955. http://dx.doi.org/10.1016/S1995-7645(12)60180-1

[4] Ray, S., Jindal, A.K., Sengupta, S. and Sinha, S. (2014) Statins: Can We Advocate Them for Primary Prevention of Heart Disease? Medical Journal Armed Forces India, 70, 270-273. http://dx.doi.org/10.1016/j.mjafi.2013.05.008

[5] Otsuki, N., Dang, N.H., Kumagai, E., Kondo, A., Iwata, S., et al. (2010) Aqueous Extract of Carica papaya Leaves Exhibits Anti-Tumor Activity and Immunomodulatory Effects. Journal of Ethnopharmacology, 127, 760-767. http://dx.doi.org/10.1016/j.jep.2009.11.024 
[6] Starley, I.F., Mohammed, P., Schneider, G. and Bickler, S.W. (1999) The Treatment of Paediatric Burns Using Topical Papaya. Burns, 25, 636-639. http://dx.doi.org/10.1016/S0305-4179(99)00056-X

[7] Joerin, L., Kauschka, M., Bonnlander, B., Pischel, I., Benedek, B. and Butterweck, V. (2014) Ficus carica Leaf Extract Modulates the Lipid Profile of Rats Fed with a High-Fat Diet through an Increase of HDL-C. PhytotherapyResearch, 28, 261-267. http://dx.doi.org/10.1002/ptr.4994

[8] Gómez-Pérez, Y., Amengual-Cladera, E., Català-Niell, A., Thomàs-Moyà, E., Gianotti, M., Proenza, A.M. and Lladó, I. (2008) Gender Dimorphism in High-Fat-Diet-Induced Insulin Resistance in Skeletal Muscle of Aged Rats. Cellular Physiology and Biochemistry, 22, 539-548. http://dx.doi.org/10.1159/000185538

[9] Kim, K.-J., Lee, O.-H., Han, C.-K., Kim, Y.-C. and Hong, H.-D. (2012) Acidic Polysaccharide Extracts from Gastrodia Rhizomes Suppress the Atherosclerosis Risk Index through Inhibition of the Serum Cholesterol Composition in Sprague Dawley Rats Fed a High-Fat Diet. International Journal of Molecular Sciences, 13, 1620-1631. http://dx.doi.org/10.3390/ijms13021620

[10] Folch, J., Lees, M. and Sloane Stanley, G.H. (1957) A Simple Method for the Isolation and Purification of Total Lipides from Animal Tissues. The Journal of Biological Chemistry, 226, 497-509.

[11] Bradford, M.M. (1976) A Rapid and Sensitive Method for the Quantitation of Microgram Quantities of Protein Utilizing the Principle of Protein-Dye Binding. Analytical Biochemistry, 72, 248-254. http://dx.doi.org/10.1016/0003-2697(76)90527-3

[12] Poe, M., Gutfreund, H. and Estabrook, R.W. (1967) Kinetic Studies of Temperature Changes and Oxygen Uptake in a Differential Calorimeter: The Heat of Oxidation of NADH and Succinate. Archives of Biochemistry and Biophysics, 122, 204-211. http://dx.doi.org/10.1016/0003-9861(67)90140-3

[13] Piñón-Zárate, G., Herrera-Enríquez, M.A., Hernández-Téllez, B., Jarquín-Yáñez, K. and Castell-Rodríguez, A.E. (2014) GK-1 Improves the Immune Response Induced by Bone Marrow Dendritic Cells Loaded with MAGE-AX in Mice with Melanoma. Journal of Immunology Research, 2014, Article ID: 158980.

[14] Standl, E. and Schnell, O. (2012) Alpha-Glucosidase Inhibitors 2012—Cardiovascular Considerations and Trial Evaluation. Diabetes\&Vascular Disease Research, 9, 163-169. http://dx.doi.org/10.1177/1479164112441524

[15] Vijayaraj, P., Muthukumar, K., Sabarirajan, J. and Nachiappan, V. (2013) Antihyperlipidemic Activity of Cassia auriculata Flowers in Triton WR 1339 Induced Hyperlipidemic Rats. Experimental and Toxicologic Pathology, 65, 135141. http://dx.doi.org/10.1016/j.etp.2011.07.001

[16] Pronin, A.V., Danilov, L.L., Narovlyansky, A.N. and Sanin, A.V. (2014) Plant Polyisoprenoids and Control of Cholesterol Level. Archivum Immunologiae et Therapiae Experimentalis, 62, 31-39. http://dx.doi.org/10.1007/s00005-013-0253-y

[17] Anandhi, R., Annadurai, T., Anitha, T., Muralidharan, A. and Najmunnisha, K. (2013) Antihypercholesterolemic and Antioxidative Effects of an Extract of the Oyster Mushroom, Pleurotus ostreatus, and Its Major Constituent, Chrysin, in Triton WR-1339-Induced Hypercholesterolemic Rats. Journal of Physiology and Biochemistry, 69, 313-323. http://dx.doi.org/10.1007/s13105-012-0215-6

[18] Silva, L.S., de Miranda, A.M., de Brito Magalhães, C.L., Dos Santos, R.C., Pedrosa, M.L. and Silva, M.E. (2013) Diet Supplementation with Beta-Carotene Improves the Serum Lipid Profile in Rats Fed a Cholesterol-Enriched Diet. Journal of Physiology and Biochemistry, 69, 811-820. http://dx.doi.org/10.1007/s13105-013-0257-4

[19] Suanarunsawat, T., Ayutthaya, W.D., Songsak, T., Thirawarapan, S. and Poungshompoo, S. (2011) Lipid-Lowering and Antioxidative Activities of Aqueous Extracts of Ocimum sanctum L. Leaves in Rats Fed with a High-Cholesterol Diet. Oxidative Medicine and Cellular Longevity, 2011, Article ID: 962025. http://dx.doi.org/10.1155/2011/962025

[20] Maki, K.C., Lawless, A.L., Reeves, M.S., Kelley, K.M., Dicklin, M.R., Jenks, B.H., Shneyvas, E. and Brooks, J.R. (2013) Lipid Effects of a Dietary Supplement Softgel Capsule Containing Plant Sterols/Stanols in Primary Hypercholesterolemia. Nutrition, 29, 96-100.

[21] Kučera, O., Lotková, H., Staňková, P., Podhola, M., Roušar, T., Mezera, V. and Cervinková, Z. (2011) Is Rat Liver Affected by Non-Alcoholic Steatosis More Susceptible to the Acute Toxic Effect of Thioacetamide? International Journal of Experimental Pathology, 92, 281-289. http://dx.doi.org/10.1111/j.1365-2613.2011.00765.X

[22] Bidkar, J.S., Ghanwat, D.D., Bhujbal, M.D. and Dama, G.Y. (2012) Anti-Hyperlipidemic Activity of Cucumis melo Fruit Peel Extracts in High Cholesterol Diet Induced Hyperlipidemia in Rats. Journal of Complementary and Integrative Medicine, 9, 22. http://dx.doi.org/10.1515/1553-3840.1580

[23] Senanayake, G.V., Fukuda, N., Nshizono, S., Wang, Y.M., Nagao, K., Yanagita, T., Iwamoto, M. and Ohta, H. (2012) Mechanisms Underlying Decreased Hepatic Triacylglycerol and Cholesterol by Dietary Bitter Melon Extract in the Rat. Lipids, 47, 495-503. http://dx.doi.org/10.1007/s11745-012-3667-0

[24] Konan, K., Justin, N.K., Lydie, B., Souleymane, M., Francis, Y.A. and David, N.J. (2015) Hepatoprotective and in Vivo Antioxidant Activity of Olax subscorpioidea Oliv. (Olacaceae) and Distemonathus benthamianus Baill. (Caesalpiniaceae). Pharmacognosy Magazine, 11, 111-116. http://dx.doi.org/10.4103/0973-1296.149723 
[25] Zhou, C., Zhou, J., Han, N., Liu, Z., Xiao, B. and Yin, J. (2015) Beneficial Effects of Neomangiferin on High Fat Diet-Induced Nonalcoholic Fatty Liver Disease in Rats. International Immunopharmacology, 25, 218-228. http://dx.doi.org/10.1016/j.intimp.2015.01.027

[26] Neustadt, J. and Pieczenik, S.R. (2008) Medication-Induced Mitochondrial Damage and Disease. Molecular Nutrition \& Food Research, 52, 780-788. http://dx.doi.org/10.1002/mnfr.200700075

[27] Weiss, H., Wester-Rosenloef, L., Koch, C., Koch, F., Baltrusch, S., Tiedge, M. and Ibrahim, S. (2012) The Mitochondrial Atp8 Mutation Induces Mitochondrial ROS Generation, Secretory Dysfunction, and $\beta$-Cell Mass Adaptation in Conplastic B6-mtFVB Mice. Endocrinology, 153, 4666-4676. http://dx.doi.org/10.1210/en.2012-1296 